\title{
Lymphoid Polyposis in An Adult Male- A Case Report
}

\author{
Shamina Islam ${ }^{1}$, Tamanna Choudhury ${ }^{2}$, Md. Shahadat Hossain ${ }^{3}$, Mohammed Kamal ${ }^{4}$ \\ ${ }^{1}$ Resident, Department of Pathology, BSMMU, ${ }^{2}$ Associate Professor, Department of Pathology, BSMMU, ${ }^{3}$ Professor, Department of \\ Surgery, BSMMU, ${ }^{4}$ Chairman and Professor, Department of Pathology, BSMMU
}

\begin{abstract}
:
Benign lymphoid polyposis is a rare histologic entity and should not be confused with malignant disease of the colon and rectum. We present a case of lymphoid polyposis in the intestine in a 26 years old male patient who was admitted for the treatment of faecal fistula. He had history of appendectomy, followed by ileostomy four years back. Physical examination revealed multiple faecal fistulae in the right lower abdomen. Right-sided hemicolectomy was done. Gross examination showed multiple polyps through out the specimen; the junction between caecum and ascending colon was found partially stenosed. Microscopy revealed polypoid structures consisting of multiple lymphoid follicles with prominent germinal centers. A stenosed area represented probable fistulous tract within the fibrosis. The final diagnosis was lymphoid polyposis based on clinical, gross and microscopic features.
\end{abstract}

Keywords: Lymphoid polyposis, Faecal fistula.

[BSMMU J 2011; 4(2):119-121]

\section{Introduction:}

Lymphoid polyposis is a rare disorder characterized by multiple sessile polyps in the recto-sigmoid colon and ileum formed by hyperplasia of lymphoid nodules with reactive germinal centers ${ }^{1,2}$. Three forms of lymphoid polyposis have been described, idiopathic, reactive and associated with hypogammaglobulinaemia. The idiopathic type is the most common and involves the small intestine and colon. This form usually occurs in children as an incidental finding as well as in individuals having resection for appendicitis, irritable bowel disease and familial polyposis ${ }^{3}$. The main concern is the differentiation from adenomatous polyposis; the differential diagnosis can be particularly difficult for complex forms of polyposis with coexistent adenomatous and lymphoid polyps. This entity may also be confused with malignant lymphoma of the gastrointestinal tract ${ }^{4}$. Benign lymphoid polyposis of the colon does not appear to have any propensity for malignant transformation, and major surgical resection is not indicated $^{5}$.

\section{Case report:}

A 26 years old male was admitted in Bangabandhu Sheikh Mujib Medical University (BSMMU) Hospital with faecal fistula in right lower abdomen for three years. He had a history of an appendectomy four years back. On the 5th post operative day he developed abdominal pain and distension for which ileostomy was performed. After one

Address of correspondence: Shamina Islam, Resident, Department of Pathology, BSMMU, Email address: ishmum652 @gmail.com year ileostomy was closed. But seven days later, he developed faecal fistula through the previous wound. Tuberculin test was positive and he also received antitubercular therapy for nine months but with no response.

At admission in BSMMU, physical examination revealed multiple faecal fistulae in the right lower abdomen. Barium enema was done which showed normal study up to ascending colon (Fig.-1). Fistulogram (Fig.-2) showed cutaneous opening in the right lumbar region, which communicated with the ascending colon. Chest X-ray showed left sided mild degree of pleural effusion. Routine haematological and biochemical profile were all within normal limits.

On January 2011, a right-sided hemicolectomy with ileocolic anastomosis was done and the specimen (terminal ileum, caecum, ascending colon) was sent to the Department of Pathology, BSMMU for histopathology. On gross examination, an $18 \mathrm{~cm}$ loop of intestine consisting of terminal ileum, caecum and ascending colon, showed multiple polyps throughout the entire lumen (Fig.-3); the largest one measured $1 \mathrm{~cm}$ and the smallest one $0.2 \mathrm{~cm}$ in diameter. Most polyps were round to oval in shape. The junction between caecum and ascending colon was found partially stenosed. Eight lymph nodes were identified. Grossly, no fistulous tract was found.

Microscopic examination revealed polypoid structures containing multiple lymphoid follicles with prominent germinal centers located mainly in the mucosa (Fig 4, 5). The stenosed area revealed granulation tissue and dense 
infiltration of chronic inflammatory cells which probably represent the fistulous tract. All the lymph nodes showed reactive changes. No granuloma or evidence of malignancy was found. The diagnosis was lymphoid polyposis. The patient had an uneventful recovery and went home after discharge with routine advice. At two months follow up the patient is asymptomatic and is doing well.

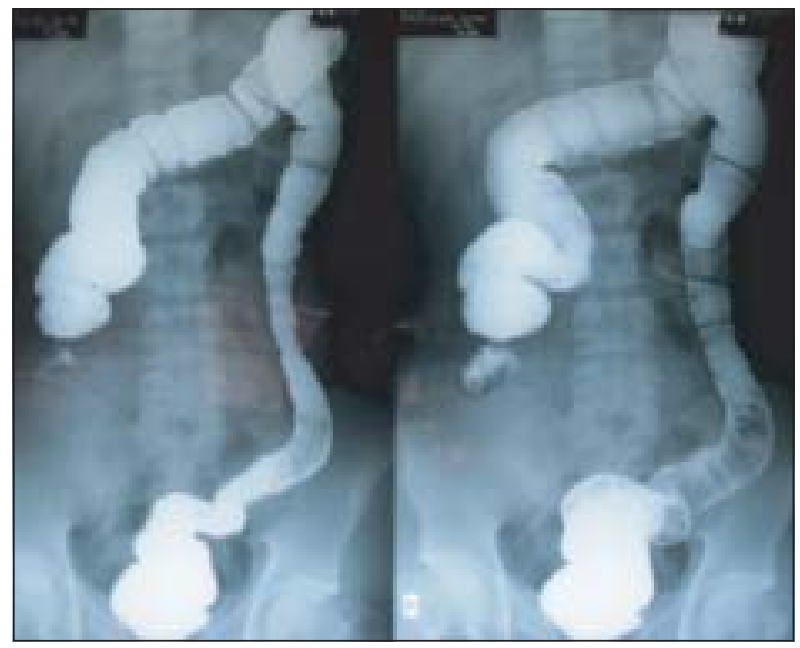

Plate-1: Barium enema showing normal study up to ascending colon

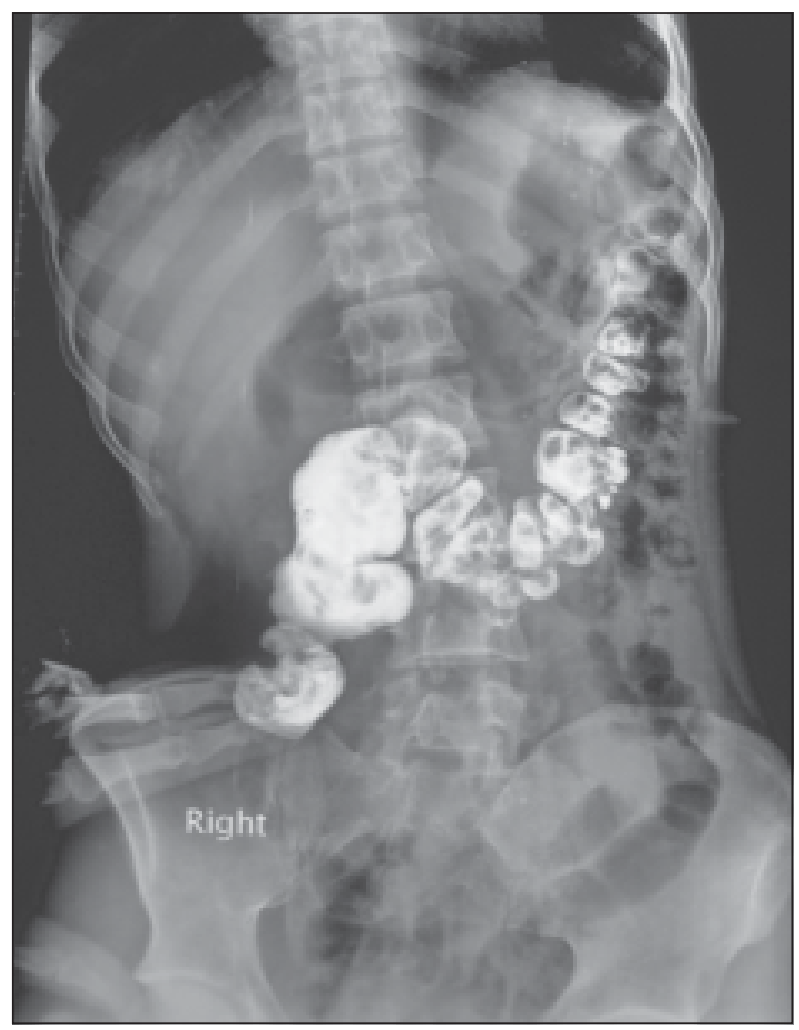

Plate-2: Fistulogram showing cutaneous opening in the right lumbar region, and communication with ascending colon

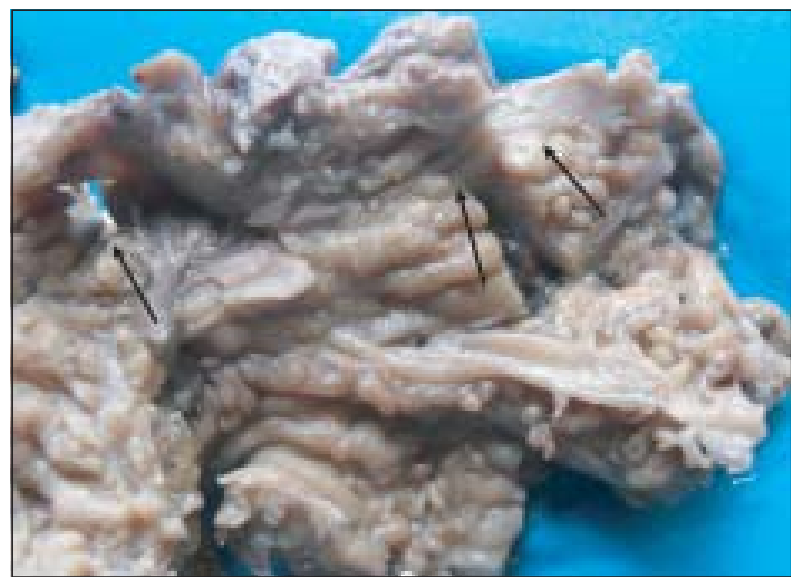

Plate-3: Multiple polyps (black arrows) in the mucosa throughout the specimen

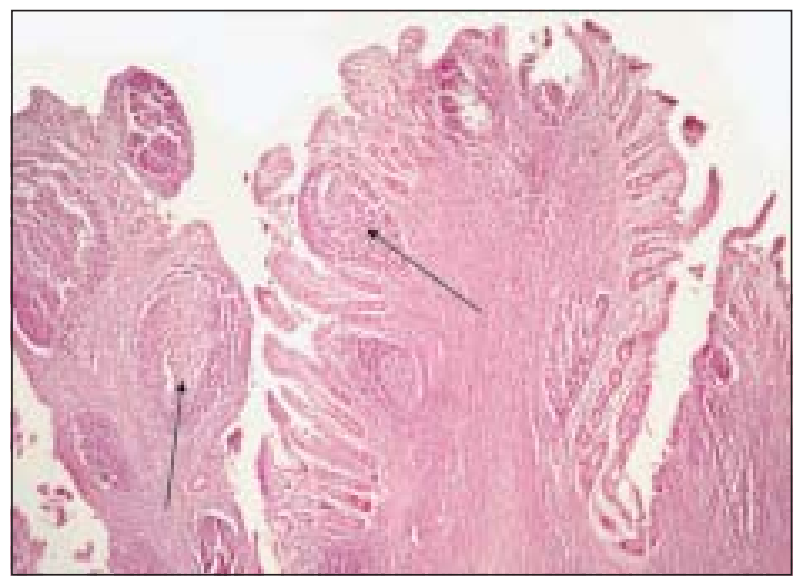

Plate-4: Polypoid structures consisting of multiple lymphoid follicles (black arrows) (H\&E X 100)

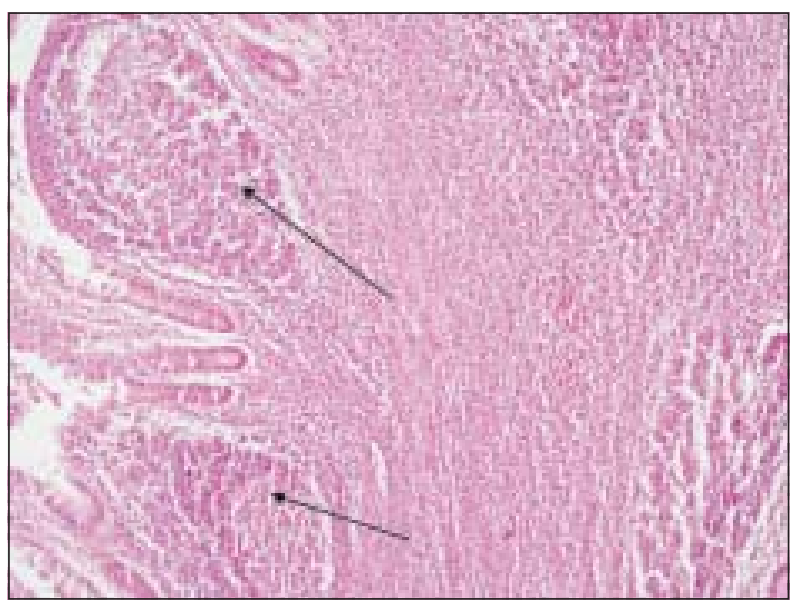

Plate-5: Multiple lymphoid follicles with prominent germinal centers located mainly in the mucosa (black arrows) (H\&E X 200). 


\section{Discussion:}

Lymphoid polyposis of the gastrointestinal tract is a benign reactive process, which is known as nodular lymphoid hyperplasia, pseudolymphoma and rectal tonsil. 1, 2, 6, 7 . Majority that occurs in children are multiple; the disease remains exceptional in adults ${ }^{5}$ and are predominantly solitary ${ }^{4}$. Our present case is an adult with multiple polyps in the terminal ileum, caecum and ascending colon having a past history of appendectomy and ileostomy. Colon et al. reported 147 children with lymphoid polyposis with lesions in large bowel (57\%) being more frequent than those in the small bowel (43\%) ${ }^{6}$. However, ileocaecal region is the most common location ${ }^{7}$. This variety leads to intussusception in children ${ }^{8}$. In other cases (nodular lymphoid hyperplasia) the entire small bowel is studded with well-circumscribed nodule of lymphoid tissue. In our case, the loop of intestine containing terminal ileum, caecum and ascending colon, showed multiple polyps through out the entire lumen. Lymphoid polyposis is usually an incidental finding on endoscopy or during examination of the resected specimen ${ }^{9}$.Several causes of lymphoid hyperplasia have been postulated. Giardia lamblia is often present. In a small minority, immunodeficiencies underlie the hyperplastic state ${ }^{7,10}$. Some of these patients have low or absent IgA and IgM level, decreased IgG and susceptibility to infection and diarrhoea ${ }^{7,10}$. There is also a reported association of lymphoid polyposis with familial adenomatous polyposis ${ }^{9,10}$.

Histologically, these lesions are located in the submucosa and are made up of lymphoid tissue with follicle formation and germinal centers ${ }^{11}$. In our case microscopy revealed polypoid structures consisting of multiple lymphoid follicles with prominent germinal centers located mainly in the mucosa. In some cases, the follicles may distort the muscularis mucosa and even extend to muscularis externa ${ }^{11}$. Tingible body macrophages are found in the germinal centers 1, 2, 4, 10. Immunostain can show the germinal centers, strongly reactive to CD20 and demonstrate the B-cell character. The Bcl-2 immunostain often fail to react in the germinal center ${ }^{2}, 10$.

The major differential diagnosis of lymphoid polyposis should be multiple lymphomatous polyposis (MLP) $)^{3}$. MLP is a distinctive and rare primary gastrointestinal lymphomas characterized by polypoid lymphomatous tissue in entire GI tract ${ }^{12}$. MLP is more common in men than in women and occurs in the fifth and sixth decades of life. The patients often present with abdominal pain, diarrhoea, hematochezia, and a palpable mass ${ }^{12}$. Vast majority of MLP are mantle cell lymphomas (MCL). The histologic feature of MCL is a monomorphic population of small lymphocytes with mantle zone formation around reactive follicles. Immunohistochemically, the MCL cells are positive for CD5, CD20 and cyclin D1, but are negative for CD23. Translocation $(11 ; 14)$ (q13; q32) is found in most MCL ${ }^{12}$, ${ }^{13}$. Histological features of our present case had typical lymphoid follicles with active germinal centre. Expanded mantle zone was not present which rules out MLP.

\section{Conclusion:}

Lymphoid polyposis is a rare but problematic disease with respect to diagnosis and treatment. However, it must be distinguished from a variety of polyposis syndromes to avoid misdiagnosis and unnecessary radical treatments.

\section{References:}

1. Weller MH, Feldman PS. Benign lymphoid polyps of the rectum. Pediatr Radiol 1975, 3:209-312.

2. Wu JF, Liou JH, Lien HC, Hsu WM, Fang YJ, Chang MH, Ni YH. Bleeding from Ileal Nodular Lymphoid Polyposis Identified by Capsule Endoscopy. J Pediatr Gastroenterol Nutr 2004, 39:295-298

3. Noffsinger A, Preiser CF, Maru D, Gilinsky N. Gastrointestinal Diseases. King DW ed. Non-neoplastic polyposis syndromes. Washington DC. Armed Forces Institute of Pathology; 2007:pp. 748-9. Atlas of Non-tumor Pathology. 1st series, fascicle 5 .

4. Li JY, Yu Z, EM Gillies. Lymphoid Polyposis Mimicking Malignant Lymphoma in Twin Girls: Case report. The Internet Journal of Pathology.2007, 6, available from: www.ispub.com/ ostia/index.php?xmlFilePath=journals/ijpa/

5. Benchimol D, Frileux P, Herve JP, Parc R. Benign lymphoid polyposis of the colon. Report of a case in an adult. Int $\mathrm{J}$ Colorectal Dis. 1991; 6(3):165-8.

6. Colon AR, DiPalma JS, Leftridge CA. Intestinal lymphonodular hyperplasia of childhood: patterns of presentation. J Clin Gastroenterol 1991, 13:163-166

7. Rosai J. Rosai and Ackermans Surgical Pathology Vol.1.9 ${ }^{\text {th }}$ ed, Missouri. Mosby; 2004.pp : 737

8. osai J. Rosai and Ackermans Surgical Pathology Vol.1.9 $9^{\text {th }}$ ed, Missouri. Mosby; 2004.pp : 727

9. Cooper HS. Intestinal neoplasms. In: Mills SE ed. Diagnostic Surgical Pathology. Vol 2. $5^{\text {th }}$ ed. Philadelphia: Lippincott Williams \& Wilkins; 2010: pp 1381

10. Mukhopadhyay S, Harbol T, Floyd FD, Sidhu JS. Polypoid Nodular Lymphoid Hyperplasia of the Terminal Ileum. Arch Pathol Lab Med 2004, 128:1186-1187.

11. Rosai J. Rosai and Ackermans Surgical Pathology Vol.1. $9^{\text {th }}$ ed, Missouri. Mosby; 2004.pp : 822

12. Vignote ML, Chicano M, Rodriguez FJ, Acosta A, Gomez F, Poyato A, Mino G. Multiple lymphomatous polyposis of the GI tract: report of a case and review. Gastrointest Endosc 2002, 56:579-582

13. Remes-Troche JM, De-Anda J, Ochoa V, Barreto-Zuniga R, Arista-Nasr J, Valdovinos MA. A rare case of multiple lymphomatous polyposis with widespread involvement of the gastrointestinal tract. Arch Pathol Lab Med 2003, 127: 1028-1030 